\title{
A survey of the attitudes, beliefs and knowledge about medical cannabis among primary care providers
}

\author{
Lindsey M. Philpot ${ }^{1,2}$, Jon O. Ebbert ${ }^{1,2^{*}}$ (D) and Ryan T. Hurt ${ }^{1}$
}

\begin{abstract}
Background: Healthcare providers play a critical role in facilitating patient access to medical cannabis. However, previous surveys suggest only a minority of providers believe that medical cannabis confers benefits to patients. Significant new knowledge about the potential benefits and harms of medical cannabis has recently emerged. Understanding current attitudes and beliefs of providers may provide insight into the ongoing challenges they face as states expand access to medical cannabis.

Methods: We conducted an electronic survey of primary care providers in a large Minnesota-based healthcare system between January 23 and February 5, 2018. We obtained information about provider characteristics, attitudes and beliefs about medical cannabis, provider comfort level in answering patient questions about medical cannabis, and whether providers were interested in receiving additional education.

Results: Sixty-two providers completed the survey (response rate 31\%; 62/199). Seventy-six percent of respondents were physicians and the average age was 46.3 years. A majority of providers believed ("strongly agree" or "somewhat agree") that medical cannabis was a legitimate medical therapy (58.1\%) and 38.7\% believed that providers should be offering to patients for managing medical conditions. A majority (>50\%) of providers believed that medical cannabis was helpful for treating the qualifying medical conditions of cancer, terminal illness, and intractable pain. A majority of providers did not know if medical cannabis was effective for managing nearly one-half of the other state designated qualifying medical conditions. Few believed that medical cannabis improved quality of life domains. Over one-third of providers believed that medical cannabis interacted with medical therapies. One-half of providers were not ready to or did not want to answer patient questions about medical cannabis, and the majority of providers wanted to learn more about it.
\end{abstract}

Conclusions: Healthcare providers generally believe that medical cannabis is a legitimate medical therapy. Provider knowledge gaps about the effectiveness of medical cannabis for state designated qualifying conditions need to be addressed, and accurate information about the potential for drug interactions needs to be disseminated to address provider concerns. Clinical trial data about how medical cannabis improves patient quality of life domains is desperately needed as this information can impact clinical decision-making.

Keywords: Cannabis, Medical marijuana, Health care surveys, Primary care physicians, Primary care

\footnotetext{
* Correspondence: ebbert.jon@mayo.edu

'Department of Medicine, Mayo Clinic, 200 1st Street SW, Rochester, MN

55905, USA

${ }^{2}$ Robert D. and Patricia E. Kern Mayo Clinic Center for the Science of Health

Care Delivery, Mayo Clinic, 200 1st Street SW, Rochester, MN 55905, USA
}

(c) The Author(s). 2019 Open Access This article is distributed under the terms of the Creative Commons Attribution 4.0 International License (http://creativecommons.org/licenses/by/4.0/), which permits unrestricted use, distribution, and reproduction in any medium, provided you give appropriate credit to the original author(s) and the source, provide a link to the Creative Commons license, and indicate if changes were made. The Creative Commons Public Domain Dedication waiver (http://creativecommons.org/publicdomain/zero/1.0/) applies to the data made available in this article, unless otherwise stated. 


\section{Background}

Cannabis is a term used for pharmacologic agents derived from plants belonging to the genus Cannabis [1]. The US Comprehensive Drug Abuse Prevention and Control Act of 1970 lists cannabis as a Drug Enforcement Agency schedule I drug with use prohibited for any purpose [2, 3]. However, 29 US states and the District of Columbia have comprehensive programs authorizing cannabis for use in specific medical conditions [4]. With the exception of the District of Columbia, all states specify the qualifying medical conditions for which cannabis can be used [5], and most states require healthcare providers to be registered with the state in order to certify patients for qualifying medical conditions. Cannabis is supplied to patients through state designated medical cannabis dispensaries. Routes of medical cannabis selfadministration vary widely by state with many providing capsules, oil, and vaporizing liquid [4]. Smoked medical cannabis is prohibited by many states as are edibles. In addition to the comprehensive programs, another 17 states have limited access cannabis laws that limit the product to a low tetrahydrocannabinol (THC) and high cannabinoid content. The majority of these limited access cannabis laws are limited to seizure indications.

The National Academies of Sciences, Engineering, and Medicine (NASEM) conducted and recently published a comprehensive review of the medical literature on the health effects of cannabis and cannabinoids [6]. NASEM concluded that there is "conclusive and substantial evidence" that medical cannabis is effective for alleviating chronic pain, chemotherapy-induced nausea and vomiting, and spasticity associated with multiple sclerosis [7]. NASEM also concluded that there is "substantial" evidence for an association between cannabis smoking and respiratory disease, and between cannabis use and motor vehicle collisions, lower birth weight offspring, and schizophrenia or other psychosis.

However, differences between cannabis products used in clinical trials and products available to patients in different states create uncertainty for healthcare providers attempting to make decisions and educate patients about medical cannabis. Data informing NASEM conclusions about the efficacy of cannabis for chronic pain, for example, included studies evaluating smoked cannabis, not available in some state dispensaries, and prescription synthetic cannabinoids, not available in any state dispensaries [8]. Different products and modes of delivery would be reasonably expected to have different benefit and risk profiles. Awareness of or concern about clinically important drug interactions between medical cannabis and other medical therapies may also heighten provider uncertainty [9].

A recent survey demonstrated that a majority of patients believe that cannabis can be used to treat pain and anxiety and reduce the amount of opioid medication used for pain management [10]. An online survey revealed that a majority of patients and the public believed sufficient safety and efficacy data exist to justify use of medical cannabis for epilepsy while only a minority of epileptologists and general neurologists believed this [11]. In a survey of Colorado primary care providers, a minority endorsed that medical cannabis conferred physical and mental benefits to patients [12]. Since the Colorado survey, several large systematic reviews $[8,13,14]$ and the NASEM report [6] have been published and more states have legalized medical cannabis. We were unable to identify any published surveys that have assessed the degree to which primary care healthcare providers believe medical cannabis is beneficial for the state designated qualifying medical conditions specific to the state of their medical practice.

In May 2014, Minnesota became the 22nd US state to create a medical cannabis comprehensive program, and enrolled patients had access to extracted cannabis products in liquid or oil form beginning on July 1, 2015. As of October 2017, 7022 Minnesotans have been certified through the Minnesota Medical Cannabis Program [15]. Qualifying conditions for medical cannabis in Minnesota currently include cancer associated with severe/chronic pain, nausea or severe vomiting, or cachexia or severe wasting; glaucoma; HIV/AIDS; Tourette syndrome; amyotrophic lateral sclerosis (ALS); seizures, epilepsy; severe and persistent muscle spasms, including those characteristic of multiple sclerosis (M.S.); inflammatory bowel disease, including Crohn's disease; terminal illness with a probable life expectancy of less than one year; intractable pain; post-traumatic stress disorder, obstructive sleep apnea, and autism.

Advancing our understanding of the attitudes, beliefs, and knowledge of practicing clinicians may identify ongoing barriers, biases and knowledge gaps relating to medical cannabis. In order to address this issue, we conducted an electronic survey of primary care providers in a health system in Midwest United States.

\section{Methods}

\section{Setting and study population}

Located within Southeastern Minnesota, Mayo Clinic manages the care for approximately 152,000 patients residing in and around Olmsted County, Minnesota through a longitudinal care practice comprised of Internal Medicine and Family Medicine providers. Primary care providers within Mayo are responsible for the longitudinal care of our local and community-based population. Longitudinal care comprises preventive and wellness care, management of chronic health conditions, addressing acute issues that arise, and coordination of care with our specialty practices as needed. A link to participate in an anonymous, 
web-based survey was sent to the institutional email addresses of a convenience sample of the 199 physicians (Medical Doctor, MD; Doctor of Osteopathy, DO; Bachelor of Medicine, Bachelor of Surgery (MBBS)), nurse practitioners (NP), and physician assistants (PA) responsible for the primary care of these patients. Respondents were allowed two weeks to complete the survey (January 23, 2018 through February 5, 2018). One initial invitation, and two reminder E-mails were sent to participants to complete the survey during the two week period.

The study was reviewed by the Mayo Institutional Review Board and determined to be exempt from the requirement for IRB approval (45 CFR 46.101b, item 2) including waiver of informed consent.

\section{Questionnaire}

The new survey tool was developed by first defining domains of interest (knowledge, attitudes, and beliefs) (Additional file 1). Questions in these domains were informed by qualitative data from patient surveys reported through the Minnesota Medical Cannabis Program. Questions were pilot tested and refined. Survey items were placed on 3- or 5-point Likert scales to garner patient agreement or perceived degree of helpfulness or frequency, based on the individual survey item. The 16-item survey was designed to address the following areas.

\section{Provider characteristics and knowledge}

We assessed clinician licensure (MD/DO/MBBS, NP/PA), primary care departments (Internal Medicine or Family Medicine), age, years in practice, and gender. We also assessed whether clinicians are registered to certify patients for medical cannabis and, if so, how many patients they have certified. In addition, we asked whether clinicians felt confident about answering patient questions about medical cannabis and whether the clinicians were interested in learning more about the topic.

\section{Provider attitudes and beliefs regarding medical Cannabis as a therapy in general}

We first assessed clinician attitudes about the legitimacy of medical cannabis as a medical therapy in general and beliefs regarding overall effectiveness. We also assessed provider beliefs that patients were using cannabis illegally to treat symptoms outside of the state program and their beliefs on the effectiveness of state designated medical cannabis as opposed to illegal cannabis used by patients. Furthermore, we asked about the perceived level of difficulty providers felt in enrolling and maintaining patients on medical cannabis therapy through the state program.
Provider beliefs about specific disease and symptom control and perceived benefits to patient quality of life

We assessed provider beliefs in how helpful medical cannabis is a medical therapy for the 13 state designated medical conditions, how helpful medical cannabis is as a medical therapy to control individual symptoms, and to what extent medical cannabis positively impacts the quality of life of patients. We assessed the following symptoms: pain, seizures, nausea and vomiting, appetite, anxiety, depression, insomnia, weight loss, and tics. Quality of life (QOL) measures included: physical functioning, energy level, mood, enjoyment of life, social engagement, ability to work, and sense of hope.

\section{Statistical analyses}

We summarized provider characteristics using summary statistics. Respondent count and proportion were calculated based on total respondents per question, and the number skipping a question was not included in the denominator. All data management and statistical analyses were performed using Statistical Analysis Software (SAS) Version 9.3 (Cary, North Carolina).

\section{Results}

\section{Provider characteristics and knowledge}

Sixty-two providers completed the survey (response rate 31\%; 62/199). Seventy-six percent of respondents were physicians and the average age was 46 years (Table 1). A minority $(27.4 \%)$ was registered to certify patients for medical cannabis, but one-half reported having patients who had been certified for medical cannabis. The mean number of patients certified by certifying providers was 4. One-half of providers were not ready or did not want to answer patient questions about medical cannabis, and over three-quarters of providers were interested in learning more about the topic.

\section{Provider attitudes and beliefs regarding medical Cannabis as a therapy in general}

A majority of providers believed ("strongly agree" or "somewhat agree") that medical cannabis was a legitimate medical therapy and over one-third believed that providers should be offering it to patients for managing medical conditions (Table 2). A majority thought it could effectively treat symptoms associated with medical conditions, but $38.7 \%$ believed that medical cannabis has significant interactions with medical therapies. A minority thought that the Minnesota state patient certification process was a barrier to enrollment. Almost all providers were aware of some of their patients using cannabis illegally to manage symptoms or medical conditions. A majority thought the cannabis acquired through the state was safer than that obtained illegally although only a minority thought it was more effective. 
Table 1 Provider Characteristics and Knowledge $(N=62)$

\begin{tabular}{|c|c|}
\hline \multicolumn{2}{|l|}{ Provider Licensure, n (\%) } \\
\hline Physician (MD, DO, MBBS) & $45(75.6)$ \\
\hline Advanced Practice Professional (NP, PA) & $17(27.4)$ \\
\hline \multicolumn{2}{|l|}{ Provider Specialty, n (\%) } \\
\hline Internal Medicine & $33(53.2)$ \\
\hline Family Medicine & $29(46.8)$ \\
\hline \multicolumn{2}{|l|}{ Age, years } \\
\hline Mean (SD) & $46.3(11.8)$ \\
\hline Median (IQR) & $43.5(36.0,58.0)$ \\
\hline Range & $27.0-65.0$ \\
\hline \multicolumn{2}{|l|}{ Gender, n (\%) } \\
\hline Female & $26(42.6)$ \\
\hline Male & $35(57.4)$ \\
\hline \multicolumn{2}{|l|}{ Registered to certify patients for medical cannabis, n (\%) } \\
\hline Yes & $17(27.4)$ \\
\hline No & $45(75.6)$ \\
\hline \multicolumn{2}{|c|}{ Number of patients certified ( $n=13$ providers report certifying) } \\
\hline Mean (SD) & $3.7(3.7)$ \\
\hline Median (IQR) & $3.0(2.0,4.0)$ \\
\hline Range & $1.0-15.0$ \\
\hline \multicolumn{2}{|l|}{ Report of ever certifying a patient, $n(\%)$} \\
\hline Yes & $16(25.8)$ \\
\hline No & $46(74.2)$ \\
\hline \multicolumn{2}{|c|}{ Report of having patients who have been certified, n (\%) } \\
\hline Yes & $20(50.0)$ \\
\hline No & $20(50.0)$ \\
\hline \multicolumn{2}{|l|}{ Interest in learning more about medical cannabis, n (\%) } \\
\hline Yes & $48(77.4)$ \\
\hline No & $14(22.6)$ \\
\hline \multicolumn{2}{|l|}{ Ready to answer questions about medical cannabis, n (\%) } \\
\hline Yes & $31(50 \%)$ \\
\hline No & $28(45.2 \%)$ \\
\hline Do not want to answer questions about cannabis & $3(4.8 \%)$ \\
\hline
\end{tabular}

SD Standard Deviation, IQR Interquartile Range

\section{Provider beliefs about specific disease and symptom} control and perceived benefits to patient quality of life A majority of providers believed that medical cannabis was helpful for treating the qualifying medical conditions of cancer, terminal illness, and intractable pain (Table 3). One-half of providers believed that it was effective for muscle spasms, including those characteristic of M.S.. Forty-two percent believed it was effective for seizures, and over one-third believed that medical cannabis was effective for glaucoma. A majority of providers did not know if it was effective for managing Tourette syndrome, amyotrophic lateral sclerosis (ALS), inflammatory bowel disease, post-traumatic stress disorder, obstructive sleep apnea, or autism. A majority of providers believed that medical cannabis was effective for managing clinical symptoms of pain, nausea and/or vomiting, and anxiety. Over one-third believed it was effective for managing insomnia. A minority of providers believed that medical cannabis improved patient physical functioning, energy, mood, enjoyment of life, social engagement, ability to work, and sense of hope.

\section{Discussion}

We observed that although primary care healthcare providers in a state with an established program generally believe that medical cannabis is a legitimate medical therapy and safer than illegal cannabis, significant knowledge gaps existed about effectiveness related to state designated qualifying medical conditions and one-half were not prepared to answer patient questions about it. Most providers indicated they were aware that some of their patients were using cannabis illegally to treat medical conditions, but few believed that medical cannabis improved patient quality of life domains. A significant proportion of providers endorsed that medical cannabis had potential interactions with medical therapies. Most providers were interested in learning more about medical cannabis.

Only three of thirteen Minnesota state designated qualifying medical conditions had a majority of providers endorsing that medical cannabis was an effective management strategy for them. However, more than one-half of providers believed that medical cannabis was effective for the management of nausea/vomiting, muscle spasms including those characteristic of M.S., and pain, three conditions for which the best evidence exists [6]. Knowledge gaps in the literature exist regarding the effectiveness of medical cannabis for different medical conditions, and data available supporting the potential efficacy of medical cannabis for state designated qualifying medical conditions varies substantially. For example, available data suggests cannabinoid use is associated with only short-term reductions in intraocular pressure [16]; the National Academies of Sciences, Engineering, and Medicine (NASEM) concluded that limited evidence suggests that they are ineffective for the treatment of glaucoma [6], one of the most common qualifying medical conditions among state medical cannabis programs [17]. States interested in maintaining medical cannabis laws for medical indications could consider a more evidence-based approach when adding additional qualifying conditions. This approach may increase the perceived legitimacy of medical cannabis for qualifying conditions among certifying clinicians and increase the likelihood that providers would consider medical cannabis as part of a comprehensive treatment strategy. 
Table 2 Provider Attitudes and Beliefs Regarding Medical Cannabis in General, N (\%)

\begin{tabular}{|c|c|c|c|c|c|}
\hline & Strongly agree & Somewhat agree & $\begin{array}{l}\text { Neither agree } \\
\text { nor disagree }\end{array}$ & Somewhat disagree & Strongly disagree \\
\hline Medical cannabis is a legitimate medical therapy. & $13(21.0)$ & $23(37.1)$ & $18(29.0)$ & $3(4.8)$ & $5(8.1)$ \\
\hline $\begin{array}{l}\text { Medical providers should be offering medical } \\
\text { cannabis for managing medical conditions. }\end{array}$ & $10(16.1)$ & $14(22.6)$ & $20(32.3)$ & $12(19.3)$ & $6(9.7)$ \\
\hline $\begin{array}{l}\text { Medical cannabis has significant interactions } \\
\text { with medical therapies. }\end{array}$ & $5(8.1)$ & 19 (30.6) & $27(43.6)$ & $9(14.5)$ & $2(3.2)$ \\
\hline $\begin{array}{l}\text { Medical cannabis can effectively treat symptoms } \\
\text { associated with medical conditions. }\end{array}$ & $13(21.0)$ & $24(38.7)$ & $20(32.3)$ & $3(4.8)$ & $2(3.2)$ \\
\hline $\begin{array}{l}\text { The process to certify patients in the medical } \\
\text { cannabis program prevents me from enrolling } \\
\text { patients. }\end{array}$ & $5(8.2)$ & $10(16.4)$ & $15(24.6)$ & $16(26.2)$ & $15(24.6)$ \\
\hline $\begin{array}{l}\text { I am aware that patients use cannabis illegally } \\
\text { to treat symptoms or medical conditions. }\end{array}$ & $41(66.1)$ & $17(27.5)$ & $2(3.2)$ & $0(0.0)$ & $2(3.2)$ \\
\hline $\begin{array}{l}\text { Medical cannabis through the state of Minnesota } \\
\text { is safer than cannabis that patients use illegally. }\end{array}$ & $21(33.9)$ & $17(27.4)$ & 19 (30.6) & $3(4.8)$ & $2(3.2)$ \\
\hline $\begin{array}{l}\text { Medical cannabis through the state of Minnesota } \\
\text { is more effective than cannabis that patients use illegally. }\end{array}$ & $6(9.8)$ & $8(13.1)$ & $37(60.7)$ & $9(14.8)$ & $1(1.6)$ \\
\hline
\end{tabular}

Most providers did not endorse that they believed medical cannabis improved aspects of patient quality of life (QOL). Systematic reviews have demonstrated that cannabinoids improve QOL among patients taking them for chronic neuropathic pain [18]. This particular review included studies evaluating dronabinol (THC), nabilone (THC biosimilar), and nabiximols (THC and cannabidiol, CBD). Such information is informative for both patients and providers in Minnesota as products available through the state program consist exclusively of THC and/or CBD. However, exceptionally few studies on medical cannabis have collected QOL measures [6] making it difficult for providers to be informed about potential benefit in these domains. Researchers should be encouraged to include quality of life measures, such as the SF-36 [19], especially in prospective studies as this questionnaire is publicly-available, validated, and easily collected. Patient QOL considerations have significant impact on provider clinical decision-making [20]. Adding QOL measures to an assessment battery along with the outcomes of interest (e.g., pain and spasticity) should not be viewed as overly burdensome and will critically advance the science.

We observed that over one-third of providers believed that medical cannabis has significant interactions with medical therapies. Providers need to be informed of potential interactions between medications they prescribe and products obtained from state dispensaries. Even when products contain only THC and CBD as constituents, providers and allied health professionals have little understanding of the concentration of these cannabinoids in the formulations patient receive from the state dispensary and this information is not loaded into electronic medical records. As a result, software automatically flagging drug interactions cannot assist prescribers. To address this concern, clinicians may stop medical cannabis in order to avoid these interactions when starting new medications, a problem that may be exacerbated in states making available smoked cannabis which contains over 100 phytocannabinoids (i.e., natural plant products) [21]. Although the evidence for significant drug interactions with THC and CBD is rare, THC and CBD are metabolized by CYP1A2, CYP2C9, CYP2C19, and CYP3A4 and serum concentrations of these molecules may theoretically increase with medications that inhibit or induce these enzymes [22]. Greater information sharing between dispensaries, patients and providers regarding the dosing of medical cannabis and the relative concentrations of medical cannabis constituent components present opportunities to improve patient safety.

We observed that $50 \%$ providers were not ready or did not want to answer patient questions about medical cannabis. This is consistent with previous research among US residents and fellows observing that only $35.3 \%$ of respondents felt ready to answer patient questions about cannabis [23]. Reassuringly, we found that over three-quarters of providers were interested in learning more about medical cannabis. Previous surveys have reported a strong desire among providers to obtain and support additional education on medical cannabis [12, 24]. Given the expansion of medical cannabis in the US, medical education and continuing medical education needs to include curricula on cannabinoids or these profound knowledge gaps will put patients and providers at risk.

The strengths of our survey include that it was conducted among primary care providers in a large, integrated healthcare system in a state where medical cannabis laws have been present for two years, we assessed beliefs about the effectiveness of medical 
Table 3 Provider Beliefs about Specific Diseases and Symptom Control, and Perceived Benefits to Patient Quality of Life, N (\%)

\begin{tabular}{|c|c|c|c|c|c|c|}
\hline & \multicolumn{2}{|l|}{ Positive } & \multirow{2}{*}{$\begin{array}{l}\text { Neutral } \\
3\end{array}$} & \multicolumn{2}{|l|}{ Negative } & \multirow{2}{*}{$\begin{array}{l}\text { Don't Know } \\
6\end{array}$} \\
\hline & 1 & 2 & & 4 & 5 & \\
\hline \multicolumn{7}{|l|}{ Qualifying Medical Conditions (H) } \\
\hline $\begin{array}{l}\text { Cancer associated with severe/chronic pain, nausea or severe } \\
\text { vomiting, or cachexia or severe wasting }\end{array}$ & $20(32.3)$ & $29(46.8)$ & $2(3.2)$ & $0(0.0)$ & $2(3.2)$ & $9(14.5)$ \\
\hline Glaucoma, missing = 1 & $3(4.9)$ & $19(31.2)$ & $7(11.5)$ & $0(0.0)$ & $2(3.3)$ & $30(49.2)$ \\
\hline HIV/AIDS & $4(6.5)$ & $12(19.4)$ & $12(19.4)$ & $0(0.0)$ & $4(6.5)$ & $30(48.4)$ \\
\hline Tourette Syndrome & $3(4.8)$ & $13(21.0)$ & $10(16.1)$ & $1(1.6)$ & $2(3.2)$ & $33(53.2)$ \\
\hline Amyotrophic Lateral Sclerosis (ALS) & $5(8.1)$ & $12(19.4)$ & $8(12.9)$ & $0(0.0)$ & $3(4.8)$ & $34(54.8)$ \\
\hline Seizures, including those characteristic of Epilepsy & $8(12.9)$ & $18(29.0)$ & $8(12.9)$ & $1(1.6)$ & $2(3.2)$ & $25(40.3)$ \\
\hline $\begin{array}{l}\text { Severe and persistent muscle spasms, including those characteristic } \\
\text { of Multiple Sclerosis }\end{array}$ & $8(12.9)$ & $23(37.1)$ & $7(11.3)$ & $0(0.0)$ & $3(4.8)$ & $21(33.9)$ \\
\hline Inflammatory bowel disease, including Crohn's disease & $3(4.8)$ & $8(12.9)$ & $12(19.4)$ & $1(1.6)$ & $5(8.1)$ & $33(53.2)$ \\
\hline Terminal illness, with a probable life expectancy of less than one year & $14(22.6)$ & $23(37.1)$ & $4(6.5)$ & $1(1.6)$ & $2(3.2)$ & $18(29.0)$ \\
\hline Intractable pain & $14(22.6)$ & $28(45.2)$ & $3(4.8)$ & $2(3.2)$ & $4(6.5)$ & $11(17.7)$ \\
\hline Post-Traumatic Stress Disorder, missing $=2$ & $5(8.3)$ & $10(16.7)$ & $11(18.3)$ & $1(1.7)$ & $2(3.3)$ & $31(51.7)$ \\
\hline Obstructive Sleep apnea & $1(1.6)$ & $2(3.2)$ & $13(21.0)$ & $4(6.5)$ & $8(12.9)$ & $34(54.8)$ \\
\hline Autism & $2(3.2)$ & $1(1.6)$ & $11(17.7)$ & $4(6.5)$ & $7(11.3)$ & $37(59.7)$ \\
\hline \multicolumn{7}{|l|}{ Symptoms $(\mathrm{H})$} \\
\hline Pain & $12(19.4)$ & $37(59.7)$ & $2(3.2)$ & $0(0.0)$ & $4(6.5)$ & $7(11.3)$ \\
\hline Seizures & $10(16.1)$ & $20(32.3)$ & $9(14.5)$ & $2(3.2)$ & $2(3.2)$ & $19(30.7)$ \\
\hline Nausea and/or vomiting & $9(14.5)$ & $33(52.3)$ & $5(8.1)$ & $3(4.8)$ & $2(3.2)$ & $10(16.1)$ \\
\hline Muscle spasms & $4(6.5)$ & $20(32.3)$ & $15(24.2)$ & $0(0.0)$ & $3(4.8)$ & $20(32.3)$ \\
\hline Anxiety & $8(12.9)$ & $28(45.2)$ & $6(9.7)$ & $6(9.7)$ & $4(6.5)$ & $10(16.1)$ \\
\hline Depression & $3(4.8)$ & $8(12.9)$ & $7(11.3)$ & $20(32.3)$ & $11(17.7)$ & $13(21.0)$ \\
\hline Sleeplessness & $4(6.5)$ & $17(27.4)$ & $12(19.4)$ & $3(4.8)$ & $6(9.7)$ & $20(32.3)$ \\
\hline Weight loss & $5(8.1)$ & $7(11.3)$ & $12(19.4)$ & $6(9.7)$ & $10(16.1)$ & $22(35.5)$ \\
\hline Tics & $3(4.8)$ & $13(21.0)$ & $9(14.5)$ & $2(3.2)$ & $2(3.2)$ & $33(53.2)$ \\
\hline \multicolumn{7}{|l|}{ Quality of Life (E) } \\
\hline Physical functioning & $4(6.5)$ & $10(16.1)$ & $18(29.0)$ & $10(16.1)$ & $4(6.5)$ & $16(25.8)$ \\
\hline Energy level & $2(3.2)$ & $4(6.5)$ & $15(24.2)$ & $9(14.5)$ & $10(16.1)$ & $22(35.5)$ \\
\hline Mood & $3(4.8)$ & $10(16.1)$ & $17(27.4)$ & $10(16.1)$ & $5(8.1)$ & $17(27.4)$ \\
\hline Enjoyment of life & $3(4.8)$ & $15(24.2)$ & $18(29.0)$ & $5(8.1)$ & $3(4.8)$ & $18(29.0)$ \\
\hline Social engagement (visiting with friends and family), missing $=1$ & $4(6.6)$ & $10(16.4)$ & $16(26.2)$ & $9(14.8)$ & $3(4.9)$ & $19(31.2)$ \\
\hline Ability to work & $2(3.2)$ & $9(14.5)$ & $12(19.4)$ & $11(17.7)$ & $8(12.9)$ & $20(32.3)$ \\
\hline Sense of hope, missing $=1$ & $4(6.6)$ & $11(18.0)$ & $14(23.0)$ & $9(14.8)$ & $4(6.7)$ & 19 (31.2) \\
\hline
\end{tabular}

(H) Helpfulness Scale (1, Very helpful; 2, Somewhat helpful; 3, Neither helpful nor not helpful; 4, Somewhat not helpful; 5, Not at all helpful; 6, Don't know) (E) Extent Scale (1, A great deal; 2, Quite a bit; 3, Somewhat; 4, Very little; 5, Not at all; 6, Don't know)

cannabis for state designated qualifying conditions, and we observed a high response rate. Our study is limited by sample size and generalizability as questions were referential to the Minnesota state cannabis program, but this program is very similar to other state programs.

\section{Conclusions}

Providers generally believe that medical cannabis is a legitimate medical therapy. Significant opportunities exist to: 1) close knowledge gaps for clinicians through the collection and dissemination of information about the effectiveness of medical cannabis for state qualifying conditions; 2) alleviate concerns about drug interactions by exploring opportunities for information sharing between dispensaries and traditional medical practices; and 3) expand the knowledge base about how medical cannabis impacts patient QOL. 


\section{Additional file}

Additional file 1: Provider Cannabis Survey. Survey Tool Sent to Providers about Medical Cannabis. (DOCX $33 \mathrm{~kb}$ )

\section{Abbreviations}

CBD: Cannabidiol; NASEM: The National Academies of Sciences, Engineering, and Medicine (NASEM); QOL: Quality of life; THC: Tetrahydrocannabinol

\section{Acknowledgements}

Not applicable

\section{Funding}

This study was funded by the Mayo Clinic. The Mayo Clinic had no role in the design and collection, analysis, and interpretation of data and in the writing of the manuscript.

\section{Availability of data and materials}

The datasets used and/or analyzed during the current study are available from the corresponding author on reasonable request.

\section{Authors' contributions}

JOE, LMP designed and funded the study, analyzed the data, and drafted the manuscript. RTH helped with data analysis and provided critical review of the manuscript. JOE, LMP, and RTH have all reviewed and approved of the manuscript.

\section{Ethics approval and consent to participate}

The study was reviewed by expedited review procedures at the Mayo Institutional Review Board and determined to be exempt from the requirement for IRB approval (45 CFR 46.101b, item 2).

\section{Consent for publication}

Not applicable

\section{Competing interests}

LMP reports grant funding from GlaxoSmithKline (GSK) outside the submitted work. No other authors have conflicts of interest to report.

\section{Publisher's Note}

Springer Nature remains neutral with regard to jurisdictional claims in published maps and institutional affiliations.

Received: 25 June 2018 Accepted: 10 January 2019

Published online: 22 January 2019

\section{References}

1. Pollio A. The name of Cannabis: a short guide for nonbotanists. Cannabis Cannabinoid Res. 2016;1(1):234-8.

2. Vigil JM, Stith SS, Adams IM, Reeve AP. Associations between medical cannabis and prescription opioid use in chronic pain patients: a preliminary cohort study. PLoS One. 2017;12(11):e0187795.

3. Public Law: The comprehensive drug abuse prevention and control act of 1970 [https://legcounsel.house.gov/Comps/91-513.pdf]. Accessed 15 Jan 2019.

4. Abuhasira R, Shbiro L, Landschaft Y. Medical use of cannabis and cannabinoids containing products - regulations in Europe and North America. Eur J Intern Med. 2018;49:2-6.

5. Klieger SB, Gutman A, Allen L, Pacula RL, Ibrahim JK, Burris S. Mapping medical marijuana: state laws regulating patients, product safety, supply chains and dispensaries, 2017. Addiction. 2017;112(12):2206-16.

6. National Academies of Sciences Engineering and Medicine (U.S.). Committee on the health effects of marijuana: an evidence review and research agenda: the health effects of cannabis and cannabinoids : the current state of evidence and recommendations for research. Washington, DC: the National Academies Press; 2017.

7. Abrams DI. The therapeutic effects of Cannabis and cannabinoids: an update from the National Academies of sciences, engineering and medicine report. Eur J Intern Med. 2018:49:7-11
8. Whiting PF, Wolff RF, Deshpande S, Di Nisio M, Duffy S, Hernandez AV, Keurentjes JC, Lang S, Misso K, Ryder S, et al. Cannabinoids for medical use: a systematic review and meta-analysis. JAMA. 2015;313(24):2456-73.

9. Rong C, Carmona NE, Lee YL, Ragguett RM, Pan Z, Rosenblat JD, Subramaniapillai M, Shekotikhina M, Almatham F, Alageel A, et al. Drugdrug interactions as a result of co-administering Delta(9)-THC and CBD with other psychotropic agents. Expert Opin Drug Saf. 2018;17(1):51-4.

10. Heng M, McTague MF, Lucas RC, Harris MB, Vrahas MS, Weaver MJ. Patient perceptions of the use of medical marijuana in the treatment of pain after musculoskeletal trauma: a survey of patients at 2 trauma centers in Massachusetts. J Orthop Trauma. 2018:32(1):e25-30.

11. Mathern GW, Beninsig L, Nehlig A. Fewer specialists support using medical marijuana and CBD in treating epilepsy patients compared with other medical professionals and patients: result of Epilepsia's survey. Epilepsia. 2015;56(1):1-6.

12. Kondrad E, Reid A. Colorado family physicians' attitudes toward medical marijuana. J Am Board Fam Med. 2013;26(1):52-60.

13. Andreae MH, Carter GM, Shaparin N, Suslov K, Ellis RJ, Ware MA, Abrams DI, Prasad $H$, Wilsey B, Indyk D, et al. Inhaled Cannabis for chronic neuropathic pain: a meta-analysis of individual patient data. J Pain. 2015;16(12):1221-32.

14. McLoughlin BC, Pushpa-Rajah JA, Gillies D, Rathbone J, Variend H, Kalakouti E, Kyprianou K. Cannabis and schizophrenia. Cochrane Database Syst Rev. 2014; (10):CD004837.

15. MN MEDIC AL CANNABIS PROGRAM UPDATE, OCTOBER 2017 [http://www. health.state.mn.us/topics/cannabis/about/update1017.pdf]. Accessed 15 Jan 2019.

16. Bowen $L L, M c R a e-C l a r k ~ A L$. Therapeutic benefit of smoked Cannabis in randomized placebo-controlled studies. Pharmacotherapy. 2017;38(1):80-5.

17. MEDICAL MARIJUANA ACCESS IN THE UNITED STATES: A Patient-Focused Analysis of the Patchwork of State Laws [http://www.safeaccessnow.org/ medical_marijuana_access_in_the_usa]. Accessed 15 Jan 2019.

18. Meng $H$, Johnston B, Englesakis M, Moulin DE, Bhatia A. Selective cannabinoids for chronic neuropathic pain: a systematic review and metaanalysis. Anesth Analg. 2017;125(5):1638-52

19. Ware JE Jr, Gandek B. Overview of the SF-36 health survey and the international quality of life assessment (IQOLA) project. J Clin Epidemiol. 1998;51(11):903-12.

20. Hajjaj FM, Salek MS, Basra MK, Finlay AY. Non-clinical influences on clinical decision-making: a major challenge to evidence-based practice. J R Soc Med. 2010;103(5):178-87.

21. Miller RJ, Miller RE. Is cannabis an effective treatment for joint pain? Clin Exp Rheumatol. 2017;35(Suppl 107(5)):59-67.

22. Russo EB. Current therapeutic Cannabis controversies and clinical trial design issues. Front Pharmacol. 2016;7:309.

23. Evanoff $A B$, Quan T, Dufault $C$, Awad M, Bierut $L$. Physicians-in-training are not prepared to prescribe medical marijuana. Drug Alcohol Depend. 2017:180:151-5

24. Carlini BH, Garrett SB, Carter GT. Medicinal Cannabis: a survey among health care providers in Washington state. Am J Hosp Palliat Care. 2017:34(1):85-91.

Ready to submit your research? Choose BMC and benefit from:

- fast, convenient online submission

- thorough peer review by experienced researchers in your field

- rapid publication on acceptance

- support for research data, including large and complex data types

- gold Open Access which fosters wider collaboration and increased citations

- maximum visibility for your research: over $100 \mathrm{M}$ website views per year

At BMC, research is always in progress.

Learn more biomedcentral.com/submissions 